\title{
Assessing Quantitative Reasoning
}

Corrine H. Taylor

Wellesley College, CTaylor1@Wellesley.edu

Follow this and additional works at: https://digitalcommons.usf.edu/numeracy

Part of the Mathematics Commons, and the Science and Mathematics Education Commons

\section{Recommended Citation}

Taylor, Corrine H.. "Assessing Quantitative Reasoning." Numeracy 2, Iss. 2 (2009): Article 1. DOI: http://dx.doi.org/10.5038/1936-4660.2.2.1 


\section{Assessing Quantitative Reasoning}

Keywords

assessment, evaluation

Creative Commons License

(c) (i) (9)

This work is licensed under a Creative Commons Attribution-Noncommercial 4.0 License 
Plan. Do. Check. Act. Strategic planners recommend the four-step, continuous PDCA cycle for implementing any major change or for ensuring continuous improvement of products or services. ${ }^{1}$ I see a version of this process being employed in our continued efforts to create a numerate society. Right now, much attention is devoted to step 3: checking on these efforts with formal assessments (often assessments of assessments) and evaluations (typically of programs).

A decade or so ago, the focus of a small but dedicated community promoting quantitative literacy (QL) was on planning: defining QL as distinct from mathematics; detailing the skill sets and scope of QL; and establishing the importance of QL in a wide array of academic fields, in various professions, and in decision-making in everyday life. ${ }^{2}$ Then came the "do" step, with a surge in the development of college-level QL courses and the implementation of programs to support QL efforts across the curriculum. ${ }^{3}$ The QL community grew substantially over this period, as did regional and national organizations to support these efforts. ${ }^{4}$ The big focus today seems to be on assessment and evaluation. How do we best assess students' QL skills; in particular, how do we ensure our tests are valid and reliable? What effects do QL programs have on students' attitudes, skills, and other outcomes? These "checks" are essential before the QL movement can fully "act" on a grand scale, first, in more colleges and universities nationwide, and perhaps down the road, in K-12 education and in the adult population at large.

Of course, there are many types of assessments, and some assessments have been underway for a very long time. Take, for instance, the quantitative reasoning $(\mathrm{QR})$ assessments ${ }^{5}$ we have administered to incoming students for over ten years now at Wellesley College to determine which students are prepared for quantitative coursework and which first need a QR course to brush up on applying logic, math, and basic statistics. Over the past ten years, we have kept data on every incoming student's responses to each of the 18 open-ended questions on the assessment. We have undertaken some analyses of the test instruments and made revisions, but the time has come to do more formal instrument assessment, especially as other colleges and universities are borrowing our assessments at their institutions. The article "Quantitative Literacy Assessments: An

\footnotetext{
${ }^{1}$ The PDCA cycle is also known as the "Shewhart cycle" or the "Deming cycle," named for quality control gurus Walter A. Shewhart and W. Edwards Deming.

${ }^{2}$ For example, see Steen (1997 and 2001).

${ }^{3}$ For a sample of QL Programs, see the table of programs listed in Madison and Steen (2008 in this journal) and Gillman (2006).

${ }^{4}$ Three such organizations are the National Numeracy Network (NNN), The Mathematics Association of America's SIGMAA-QL, and the North East Consortium on Quantitative Literacy (NECQL).

${ }^{5}$ Wellesley's QR Assessment is available in a booklet (Wellesley College, 2007).
} 
Introduction to Testing Tests" by Dorothy Wallace et al. in this issue of Numeracy will help us and others perform those important checks, with its clear step-by-step guide to the testing process.

One assessment mentioned in the Wallace article is the "Mathematics Attitude Survey," developed by Jane Korey at Dartmouth. My QR colleague and I were made aware of this survey at the very first NNN meeting we attended in July 2001, and we adopted it at Wellesley College immediately and have used it each year since. Other institutions have also made use of the Dartmouth attitude assessment to measure changes in students" "perceived mathematical ability and confidence, their interest and enjoyment in mathematics, their belief that mathematics contributes to personal growth, and the belief that mathematics contributes to career success." " I hope that more institutions will also adopt this excellent (and carefully tested) instrument for assessing students' changes in attitudes after having taken QR coursework.

For assessing students' QL skills, I am impressed with the variety of instruments that have been developed and are being tested-each for different specific purposes. Here I briefly describe three that illustrate the scope of these instruments and their testing: (1) the QR test for students who have completed their general education requirements at James Madison University (JMU); (2) the Association of American Colleges and Universities' (AAC\&U's) Quantitative Literacy VALUE (Valid Assessment of Learning in Undergraduate Education) Rubric for assessing QL as evidenced in students' electronic portfolios; and (3) Carleton College's rubric for assessing quantitative reasoning as evidenced in their students' sophomore writing portfolios.

JMU's QR Test is narrow and deep. This 26-item, computerized, multiplechoice test ${ }^{7}$ is designed to measure two specific learning objectives: How well students "(1) use graphical, symbolic, and numerical methods to analyze, organize, and interpret natural phenomena; and (2) discriminate between association and causation, and identify the types of evidence used to establish causation." Donna Sundre, Executive Director of JMU's Center for Assessment and Research Studies, and her colleagues Christopher Murphy and Mary Handley have contributed a profile on this assessment project $^{8}$ to our new collection ${ }^{9}$ started at the workshop "NSF Projects Supporting QL Education" attached to the NNN Annual Meeting in Bothell, WA, two months ago. The psychometric

\footnotetext{
${ }^{6}$ For details on the four attitude scales - Ability, Interest, Personal Growth, and Utility - see Korey (2000, p. 7), which is available online.

${ }^{7} \mathrm{http} / / /$ www.jmu.edu/assessment/resources/prodserv/instruments_qr.htm (accessed June 21, 2009).

8 "Advancing Assessment of Scientific and Quantitative Reasoning" http://serc.carleton.edu/nnn/numeracyprojects/examples/32007.html (accessed June 21, 2009).

${ }^{9} \mathrm{http} / / /$ serc.carleton.edu/nnn/news/numeracyprojects/profiles.html (accessed June 21, 2009).
} 
analyses of these assessment instruments and the descriptions of the evaluations by these assessment experts are particularly strong. I recommend this profile to anyone interested in test assessment.

The AAC\&U's QL rubric, in contrast to the JMU test, is much broader in scope. The QL rubric is one of fourteen rubrics designed to assess what the AAC\&U has defined as "essential learning outcomes" in undergraduate education, as indicated in various components of students' electronic portfolios. ${ }^{10}$ Each of these rubrics is designed as a matrix with four performance levels (indicating progressively more sophisticated understanding) and multiple performance categories. The most recent draft of the QL rubric includes six performance categories: interpretation, representation, calculation, application and analysis, assumptions, and communication. Details are provided for each category; e.g., application and analysis is defined as the "ability to make judgments and draw appropriate conclusions based on the quantitative analysis of data, while recognizing the limits of this analysis." These rubrics are currently being tested on several AAC\&U VALUE Leadership and Partnership campuses. The final draft of the QL rubric is expected to be made public in September 2009. This rubric may be helpful at institutions looking to evaluate a wide array of student learning outcomes in QL.

The third instrument is Carleton College's rubric for assessing QR in rhetoric. In this issue of Numeracy, Nathan Grawe and Carol Rutz describe how Carleton capitalized on its highly successful writing-across-the-curriculum program to develop an assessment of QR as evidenced in their students' sophomore writing portfolios. Their article provides the philosophical underpinnings, goals and outcomes for examining QR in students' written arguments; details their experience in developing their Quantitative Inquiry, Reasoning, and Knowledge (QuIRK) program; ${ }^{11}$ and highlights the many advantages of this interdisciplinary approach. Their article here does not go into detail on Carleton's careful assessment of their QR rubic (which examines both the degree to which student uses QR to support claims and the quality of such evidence when applied); that is the subject for a future article, I hope, but for those interested in checking out the rubric, it is available on the QuIRK Web site. $^{12}$

\footnotetext{
${ }^{10}$ For more details on the VALUE project and the rubrics, see http://www.aacu.org/value/metarubrics.cfm (accessed June 21, 2009)

${ }^{11}$ For a description of QuIRK's assessment of QR in student writing, see http://serc.carleton.edu/quirk/Assessment/index.html (accessed June 21, 2009).

${ }^{12}$ Carleton College's QR in student writing rubric is still being tested and revised. The current draft of the rubric is found at http://serc.carleton.edu/files/quirk/quirk_rubric.v5.doc (accessed June 21, 2009).
} 
Last October, Carleton's QuIRK initiative and Project Kaleidoscope (PKAL) teamed up to convene a three-day workshop for 24 institutional teams to learn about more-established QR efforts, to develop action plans for enhancing QR programming on their own campuses, and to create assessment and evaluation plans for that work. ${ }^{13}$ Abstracts for some of the teams' action plans are available on the QuIRK Web site. ${ }^{14}$ These abstracts may be helpful for members of other institutions who are also beginning to assess their QR efforts. There is currently talk of convening another such workshop for other interested institutions, perhaps in conjunction with an NNN meeting. Stay tuned for more information on that possibility.

As more and more institutions enhance their QL/QR efforts, the importance of assessment and evaluation grows. Not only are individual colleges and universities clamoring for more information about various ways to assess numeracy on their campuses, but accrediting agencies such as the New England Association of Schools and Colleges (NEASC) are showing more interest in assessing students' quantitative skills and the effectiveness of QR programs. ${ }^{15}$ There are some great resources available to help institutions that are entering the "check" phase of the PDCA cycle. Please think of Numeracy not only as a place to come for help, but also as a place to submit your own studies that will help others. Working together to share such information will allow the QL movement move forward to that "act" phase. Our NNN vision of "a society in which all citizens possess the power and habit of mind to search out quantitative information, critique it, reflect upon it, and apply it in their public, personal and professional lives" depends on our collective efforts.

\section{References}

Gillman, Rick. 2006. Current Practices in Quantitative Literacy. Washington, DC: Mathematical Association of America.

Korey, Jane. 2000. "Dartmouth College Mathematics Across the Curriculum Evaluation Summary: Mathematics and Humanities Courses." http://www.math.dartmouth.edu/ matc/Evaluation/humeval.pdf (accessed June 21, 2009)

\footnotetext{
${ }^{13}$ See http://serc.carleton.edu/quirk/pkal workshop08/index.html for more information about the workshop's goals (accessed June 21, 2009).

${ }^{14}$ See http://serc.carleton.edu/quirk/pkal_workshop08/action_plans.html for the action plans (accessed June 21, 2009).

${ }^{15}$ Assessing QR is to be the subject of one of the NEASC's panels at their December 2009 regional meeting.
} 
Madison, Bernard L. and Lynn Arthur Steen. 2008. "Evolution of Numeracy and the National Numeracy Network," Numeracy: Vol. 1: Iss. 1, Article 2. http://dx.doi.org/10.5038/1936-4660.1.1.2 (accessed June 21, 2009).

Steen, Lynn Arthur, ed. 2001. Mathematics and Democracy: The Case for Quantitative Literacy. Princeton, NJ: National Council on Education and the Disciplines. http://www.maa.org/Q1/mathanddemocracy.html (accessed June 21. 2009).

Steen, Lynn Arthur, ed. 1997. Why Numbers Count: Quantitative Literacy for Tomorrow's America. New York, NY: The College Board.

Wellesley College. 2007. "Study Packet for the Quantitative Reasoning Assessment." http://serc.carleton.edu/files/nnn/teaching/wellesley_qr_booklet.pdf (accessed June 21, 2009). 